University of Nebraska - Lincoln

DigitalCommons@University of Nebraska - Lincoln

$5-2020$

\title{
Revisiting the Role of Augmentative and Alternative Communication in Aphasia Rehabilitation
}

\author{
Aimee Dietz \\ University of Cincinnati, dietzae@ucmail.uc.edu \\ Sarah Wallace \\ Duquesne University,wallaces@duq.edu \\ Kristy Weissling \\ University of Nebraska - Lincoln, kristy.weissling@unl.edu
}

Follow this and additional works at: https://digitalcommons.unl.edu/specedfacpub

Part of the Special Education and Teaching Commons

Dietz, Aimee; Wallace, Sarah; and Weissling, Kristy, "Revisiting the Role of Augmentative and Alternative Communication in Aphasia Rehabilitation" (2020). Special Education and Communication Disorders Faculty Publications. 217.

https://digitalcommons.unl.edu/specedfacpub/217

This Article is brought to you for free and open access by the Department of Special Education and Communication Disorders at DigitalCommons@University of Nebraska - Lincoln. It has been accepted for inclusion in Special Education and Communication Disorders Faculty Publications by an authorized administrator of DigitalCommons@University of Nebraska - Lincoln. 


\title{
Revisiting the Role of Augmentative and Alternative Communication in Aphasia Rehabilitation
}

\author{
Aimee Dietz, ${ }^{1}$ Sarah E. Wallace, ${ }^{2} \&$ Kristy Weissling 3
}

1 Department of Communication Sciences \& Disorders, University of Cincinnati, OH 2 Department of Speech-Language Pathology, Duquesne University, Pittsburgh, PA 3 Department of Special Education and Communication Disorders, University of Nebraska-Lincoln

Corresponding Author: Aimee Dietz: aimee.diez@uc.edu

\begin{abstract}
Purpose - The purpose of this article is to revisit the role of augmentative and alternative communication (AAC) in post stroke aphasia rehabilitation. The authors' intent is to provide a viewpoint that expands the use of AAC in post stroke aphasia rehabilitation. Specifically, we seek to clarify the role of AAC in restorative and participation approaches to aphasia rehabilitation while also considering the role of AAC in a comprehensive treatment plan. The authors support their viewpoint with citations from both the historic and contemporary literature on aphasia rehabilitation.

Conclusions - A thought-provoking viewpoint on the role of AAC in post stroke aphasia rehabilitation is proposed. More specifically, the versatility of AAC strategies is reviewed, with an emphasis on how AAC can be used to empower people with aphasia to fully participate and engage in life activities with increased independence. Moreover, we argue that AAC can be viewed as a dual-purpose tool that can simultaneously serve to drive inter-systemic reorganization resulting in some improved language performance-and perhaps restoration of language function-while offering a communication alternative during inevitable anomic events.
\end{abstract}

Published in American Journal of Speech-Language Pathology, Vol. 29, 909-913, May 2020 doi:10.1044/2019_AJSLP-19-00041

Copyright (C) 2020 American Speech-Language-Hearing Association

Submitted August 9, 2019; revised October 11, 2019; accepted November 14, 2019. 
The participation model for augmentative and alternative communication (AAC; Beukelman \& Mirenda, 2013) underscores the importance of the nature of AAC assessment requiring clinicians to concurrently address a person's needs "today" while preparing for "tomorrow" (Beukelman \& Mirenda, 2013, p. 109). Key to this model is an emphasis on assessing/ reassessing a person's potential to "increase natural ability" (p. 117) while focusing on participation needs. The participation model does not characterize AAC and traditional restorative treatments as mutually exclusive; instead, these are interdependent elements required for successful participation in meaningful activities, an approach compatible with the Life Participation Approach to Aphasia (LPAA; Chapey et al., 2000; LPAA Group et al., 2008). As such, we offer a thought-provoking examination of the role of AAC in aphasia rehabilitation.

\section{Trends in AAC Use in Aphasia}

According to the American Speech-Language-Hearing Association (ASHA) Practice Portal (ASHA, 2019) on AAC, AAC can be defined as an "...integrated group of components to enhance communication." Oftentimes, when AAC is considered, only aided supports come to mind. These include low-tech strategies such as writing, photos, objects, and communication books as well as high-tech options that include speechgenerating devices, and $\mathrm{AAC}$ communication applications (i.e., apps) on mobile technologies and/or dedicated AAC devices. However, it is imperative to understand that AAC also refers to unaided approaches such as facial expressions, body language, and gestures. People often use both aided and unaided AAC strategies, depending on the communication context of the situation (i.e., topic, listener, time of day) and disease progression or recovery.

The use of AAC as compensation for expressive communication impairments in aphasiology has a long history; Garrett et al.'s (1989) seminal case study documented how a low-tech AAC system could be implemented for people with aphasia (PWA). Since then, though, common issues we have observed in AAC implementation include (a) the use of strategies to support expression of basic needs- without regard for other purposes of communication, (b) the use of AAC only with people with the most severe aphasia, and (c) prioritization of traditional restorative treatment over compensatory/combined approaches. 
These phenomena may, in part, be driven by reimbursement and medical necessity.

Recent developments highlight the need for AAC to be better integrated into the rehabilitation plans for PWA. The Communication Bill of Rights (Brady et al., 2016)-endorsed by the National Joint Committee for the Communication Needs of Persons with Severe Disabilities-outlines 15 basic communication rights, including access to AAC, which are inherent to people with disabilities. The Bill of Rights asserts the right to maintain and develop relationships, which may be accomplished through AAC interventions that extend beyond the communication of basic needs. The rights outlined in the document are accomplished through high-quality patient-provider communication. Specifically, people with a disability have the right to communicate effectively with health care providers regarding complex and robust ideas. The notion of ensuring that PWA have an alternative or augmentative way to communicate aligns with No. 4 from Simmons-Mackie et al.'s (2017) Top 10: Best Practice Recommendations for Aphasia:

4 No one with aphasia should be discharged from services without some means of communicating his or her needs and wishes (e.g., using AAC, supports, trained partners) or a documented plan for how and when this will be achieved (Level: Good Practice Point). (p. 139)

Despite these recent developments, the trends observed in aphasia rehabilitation seem to persist. However, an integration of rehabilitation models specific to aphasia and AAC may assist with moving the field forward.

\section{LPAA: Beyond Needs, Picture Boards, and Talking Boxes}

Proponents of the LPAA prompted development of Living with Aphasia: Framework for Outcome Measurement (A-FROM) (Kagan et al., 2008), which was designed to aid clinicians, researchers, and policy makers in thinking about aphasia outcomes by addressing various factors that affect success while living with aphasia. Kagan et al. offer four domains that affect the life engagement of a person with aphasia, namely, (a) communication and language environment; (b) severity of aphasia; (c) personal identity, attitudes, and feelings; and 
Living with Aphasia: Framework for Outcome Measurement (A-FROM)

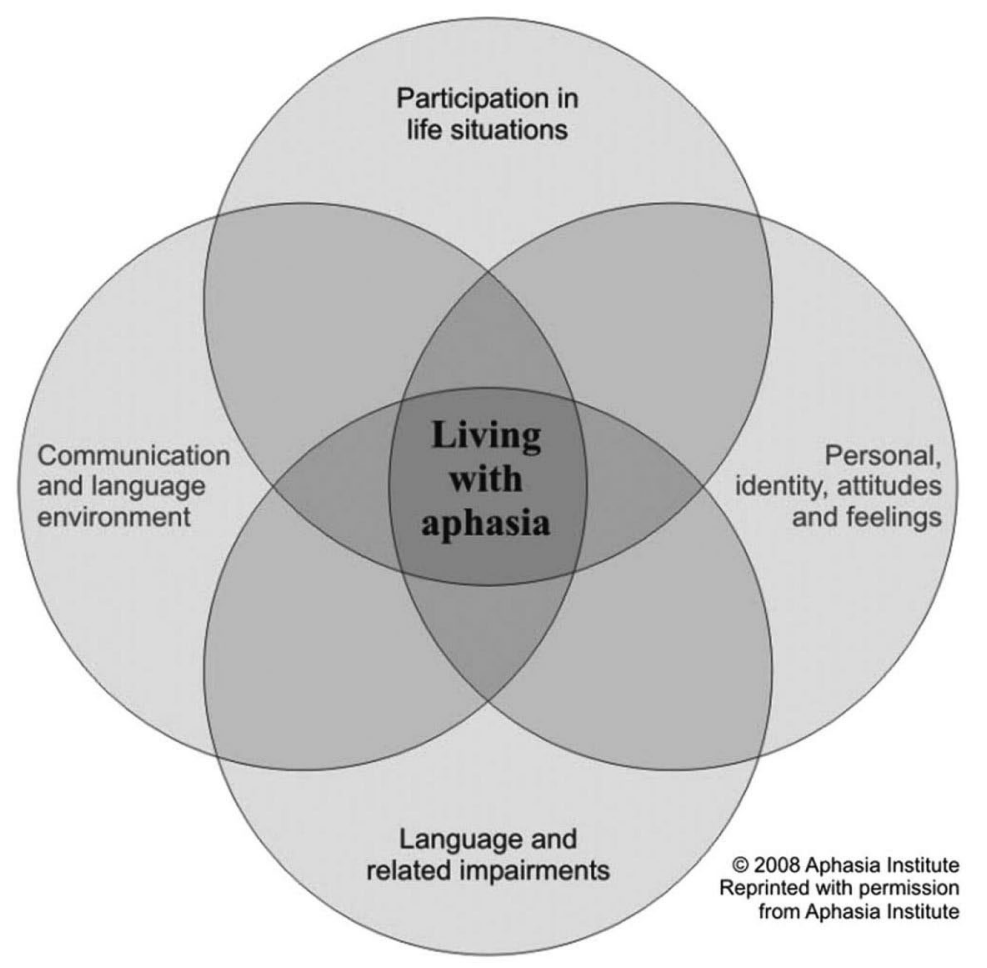

Kagan, A., Simmons-Mackie, N., Rowland, A., Huijbregts, M., Shumway, E., McEwen, S., Threats, T., \& Sharp, S., (2007). Counting what counts: A framework for capturing real-life outcomes of aphasia intervention. Aphasiology, 22 (3), 258-280.

Figure 1. From Kagan et al.'s (2008) "Counting what counts: A framework for capturing real-life outcomes of aphasia intervention.”

(d) participation in life situations (see Figure 1), and thus may serve as a guide assessment and intervention as it relates to AAC. Parallels are evident between the A-FROM domains and the levels of participation and environmental factors within the World Health Organization International Classification System (World Health Organization, 2001). We assert that when integrated into aphasia rehabilitation, AAC can positively influence all four A-FROM domains as well as multiple levels of the World Health Organization International Classification System. Typically, AAC treatment is multimodal (e.g., a combination of aided and unaided AAC components) and, ideally, would be implemented alongside traditional restorative interventions that 
serve to achieve the same life participation goals. This approach allows the person with aphasia to recover as much language as possible and, thereby, work to reduce overall aphasia severity; however, AAC instruction provides a backup plan for the person with aphasia to use when the inevitable anomic events occur during the interactions of the desired activity. In addition, as discussed below, we also contend that AAC may be used to enhance natural language ability. As such, we maintain that AAC treatment has the potential to simultaneously strengthen the communication and language environment while reducing the pressure of relying solely on independent retrieval of the target concept(s).

AAC also provides the necessary support required for the PWA to achieve Light's original four purposes of communication (Light, 1988): (a) communicate basic needs, (b) deliver information, (c) maintain social closeness, and (d) use social etiquette. As previously mentioned, basic needs (and social etiquette) are commonly included in AAC systems; however, building capacity to maintain relationships and send and receive information commonly requires conversation. Discourse between PWA and their communication partners is often described as co-constructed interactions (e.g., Bloch \& Beeke, 2008). These co-constructions may require PWA to rely on the assistance of their partner. Although some PWA may be independent communicators, with either an innate or learned (via therapy) ability to use AAC tools and strategies to actively co-construct the message with their partner, others are partner dependent (Garrett \& Lasker, 2013). When PWA are dependent communicators, it is essential that clinicians actively work to adapt the environment and identify AAC facilitators (Beukelman et al., 2008; Binger et al., 2012) who can be trained as communication partners. It is critical that clinicians help PWA learn how to take control of communicative interactions if and when the environment and partners are not optimal. The ability to communicate self-advocacy via AAC strategies fits firmly within the A-FROM domain of personal identity, attitudes, and feelings. As such, a therapeutic approach that includes the goal of self-advocacy and instruction for the PWA to learn strategies is paramount.

PWA also have a need for social closeness (Light, 1988). Mobile technology and the asynchronous communication unique to social media may offer additional options for social interactions. Smartphones have made adults without disabilities natural augmented 
communicators. It is typical for people to use the photos on their phone to share images that contextualize their story telling. Social media platforms (e.g., Facebook, Twitter) allow PWA to remain connected without the high demands of synchronous communication and employ communication strategies that may enhance the strengths of PWA (e.g., visual processing). As such, mobile devices may help PWA express themselves and co-construct messages. These activities fit firmly within the A-FROM domains (Kagan et al., 2008) of identity, attitudes, and feelings, as well as participation.

\section{Using AAC to Enhance Natural Abilities}

AAC is frequently applied with a very restricted scope, with emphasis placed on the compensatory function. That is, AAC is most often perceived as a replacement for impaired speech or language (ASHA, 2019), whereas use of AAC strategies to remediate linguistic skills in PWA is less common. One strategy PWA use to facilitate spoken language during anomic events or communication breakdowns is self-cuing. For example, they might spontaneously point to the first letter of the target (via a letter board or AAC device) then speak the word (Dietz et al., 2014, 2018; Garrett et al., 1989). Similarly, it is also common for PWA to self-cue with the initial letter or letters of a word produced either in the air or on paper (Wambaugh \& Wright, 2007). Drawing also shows promise to support selfcue during anomic events (Farias et al., 2006; Kinney et al., 2019). The literature on gestural treatment is fairly substantial regarding self-cuing as a means to facilitate word retrieval (e.g., Raymer et al., 2006).

This is in direct contrast to proponents of constraint-induced aphasia therapy, who contend that AAC promotes "learned nonuse" (Pulvermüller \& Berthier, 2008, p. 569) because use of AAC effectively rewires the brain to disassociate the act of speaking from the communication act (Pulvermüller \& Berthier, 2008). In essence, this idea perpetuated the myth that AAC interferes with language recovery. However, another theory exists that may elucidate how AAC assists spoken expression. Luria's (1972) theory of inter-systemic reorganization posits that a weak system can be restored or strengthened during intervention when it is paired with a stronger or intact system. As such, AAC intervention could be exploited to promote self-cuing or restoration of linguistic function. This approach to AAC implementation 
may help to avoid the possibility of "learned nonuse" (Pulvermüller \& Berthier, 2008, p. 569) of spoken language, and perhaps promote language recovery due to coupling the canonical language and visual processing neural networks (e.g., Dietz et al., 2018).

Going forward, it will be important to examine whether improved self-cuing of spoken language production and linguistic improvements during specific tasks can be maintained. To date, several AAC treatment studies have documented improvements in spoken discourse to naïve listeners (e.g., Dietz et al., 2018) and increased aphasia battery scores (e.g., Dietz et al., 2018; Hough \& Johnson, 2009; Johnson et al., 2008). Although these results may not translate into improved linguistic function during everyday interactions or life participation, they offer encouraging data that compel us to rethink how AAC is implemented for PWA. Perhaps, then, if future studies demonstrate improved linguistic performance (and cortical reorganization), PWA will increase acceptance of AAC as a valid treatment approach-no matter what aphasia severity (or type). This will be an important factor for researchers to examine as this knowledge base grows-especially in the acute stages of aphasia rehabilitation.

\section{Earlier Introduction of $A A C$}

A recent survey (Elman et al., 2016) revealed that only 50\% of caregivers reported receiving education about AAC approaches from the speech-language pathologist during the first 3 months of poststroke. In our experience, $\mathrm{AAC}$ is not often prescribed in early stages of recovery, and if it is, AAC is most likely to be recommended when the aphasia is so severe that PWA are unable to produce useable spoken language. At times, AAC interventions may not be included in treatment plans for PWA. Data from the ASHA National Outcomes Measurement Systems revealed that of 862 postacute patients with aphasia and apraxia of speech, 13\% received AAC (Rogers et al., 2014). This percentage fell to $2 \%$ when people with apraxia of speech were removed from the data. Increased consistency in AAC implementation is necessary to assure that PWA do not have unmet communication needs after discharge from traditional speech-language therapy (LaPointe, 2011). We believe that implementation of AAC strategies for a wide variety of communication needs, provided early in rehabilitation alongside traditional therapy, may result in increased acceptance 
of AAC and better long-term participation outcomes. This may help reduce the aforementioned "learned nonuse" (Pulvermüller \& Berthier, 2008, p. 569) and perhaps even improve spoken language. This is important because PWA are at a high risk for learned nonuse of language during early stages of recovery (Hersh et al., 2016).

We posit that the introduction of AAC, early in the stroke recovery process, may yield widespread positive effects. That is, PWA may feel more confident (and motivated) to communicate in a variety of situations because they have a reliable backup plan (i.e., AAC) if their language system fails to meet their communication needs. Earlier introduction of AAC is analogous to a physical therapist providing a patient with an aid to promote ambulation despite hemiparesis that prohibits safe, independent walking. The physical therapist does not wait for people to walk independently before allowing them to move around in their environment (Weissling \& Prentice, 2010). Depending on the situation, even people with mild paresis, ataxia, or spasticity may have difficulty ambulating safely and may need assistive equipment (e.g., quad canes, walkers) to achieve ambulation goals. As such, we ask, Why should PWA wait until they fully recover their language system before they communicate? The answer is simple: They shouldn't! Instead, clinicians should teach them how to use available AAC strategies to compensate for the anomic events they will experience, while guiding them to self-cue spoken language whenever possible.

A potential barrier to earlier implementation of AAC for PWA is the seeming permanence of its use. ASHA defines AAC as potentially temporary; however, the sole example of temporary use in the example is postoperative (ASHA, 2019). Perhaps the sense of permanency is why PWA (and their families) are apprehensive about using AAC; they may fear that the introduction of AAC marks the end of their recovery process. Earlier introduction of AAC strategies would help dispel the myth that AAC is used solely for people who will not recover speech ability. Access to AAC strategies may empower PWA to actively participate in their health care decision making, experience increased participation in life events, and reclaim-or discover new-social roles.

\section{Conclusions}

In this article, we proposed a thought-provoking viewpoint regarding the role of AAC in poststroke aphasia rehabilitation, with the goals 
of reorienting readers to the versatility of AAC strategies and emphasizing that AAC can be used to empower PWA to fully participate and engage in life with increased independence. We also argued that AAC strategies and traditional restorative approaches are not mutually exclusive and that AAC can be viewed as a dual-purpose tool that can simultaneously drive inter-systemic reorganization with potential to support language function while compensation during breakdowns. We believe that the increasing use of mobile technology to communicate via photographs and apps is creating a paradigm shift in AAC by normalizing the use of communication supports. As knowledge about neural plasticity and language recovery advance, we are confident that AAC will become a vital aphasia rehabilitation tool that supports increased participation outcomes for PWA.

Acknowledgments - This article was supported in part by National Institute on Deafness and Other Communication Disorders Grant R15 DC017280-01: A Preliminary Study of the Neurobiology of AACInduced Language Recovery in Post-Stroke Aphasia (PI: Aimee Dietz). The authors would like to thank Narae Hyun for her comments on earlier versions of this article.

\section{References}

American Speech-Language-Hearing Association. (2019). Practice portal: AAC. http://www.asha.org/Practice-Portal/Professional-Issues/ Augmentative-and-Alternative-Communication/

Beukelman, D. R., Ball, L. J., \& Fager, S. (2008). An AAC personnel framework: Adults with acquired complex communication needs. Augmentative and Alternative Communication, 24(3), 255-267.

Beukelman, D. R., \& Mirenda, P. (Eds.). (2013). Augmentative \& alternative communication: Supporting children and adults with complex communication needs (4th ed.). Brookes.

Binger, C., Ball, L., Dietz, A., Kent-Walsh, J., Lasker, J., Lund, S., McKelvey, M., \& Quach, W. (2012). Personnel roles in the AAC assessment process. Augmentative and Alternative Communication, 28(4), 278-288.

Bloch, S., \& Beeke, S. (2008). Co-constructed talk in the conversations of people with dysarthria and aphasia. Clinical Linguistics \& Phonetics, 22(12), 974-990.

Brady, N. C., Bruce, S., Goldman, A., Erickson, K., Mineo, B., Ogletree, B. T., Paul, D., Romski, M. A., Sevcik, R., Seigel, E., Schoonover, J., Snell, M., Sylvester, L., \& Wilkinson, K. (2016). Communication services and supports for individuals with severe disabilities: Guidance for assessment and intervention. American Journal on Intellectual and Developmental Disabilities, 121(2), 121-138. 
Chapey, R., Duchan, J. F., Elman, R. J., Garcia, L. J., Kagan, A., Lyon, J. G., \& Simmons-Mackie, N. (2000). Life participation approach to aphasia: A statement of values for the future. The ASHA Leader, 5(3), 4-6.

Dietz, A., Vannest, J., Maloney, T., Altaye, M., Holland, S. H., \& Szaflarski, J. P. (2018). The feasibility of improving discourse in people with aphasia through AAC: Clinical and functional MRI correlates. Aphasiology, 32(6), 693-719.

Dietz, A., Weissling, K., Griffith, J., McKelvey, M., \& Macke, D. (2014). The Impact of interface design during an initial hightechnology AAC experience: A collective case study of people with aphasia. Augmentative and Alternative Communication, 30(4), 314-328.

Elman, R. J., Cohen, A., \& Silverman, A. (2016). Perceptions of speech-language pathology services provided to persons with aphasia: A caregiver survey. Paper presented at the Clinical Aphasiology Conference, Charlottesville, Virginia, United States.

Farias, D., Davis, C., \& Harrington, G. (2006). Drawing: Its contribution to naming in aphasia. Brain and Language, 97(1), 53-63.

Garrett, K., Beukelman, D. R., \& Low-Morrow, D. (1989). A comprehensive augmentative communication system for an adult with Broca's aphasia. Augmentative and Alternative Communication, 5(1), 55-61.

Garrett, K., \& Lasker, J. (2013). Adults with severe aphasia and apraxia of speech. In D. R. Beukelman \& R. Miranda (Eds.), Augmentative \& alternative communication: Supporting children \& adults with complex communication needs (4th ed.). Brookes.

Hersh, D., Godecke, E., Armstrong, E., Ciccone, N., \& Bernhardt, J. (2016). "Ward talk": Nurses' interaction with people with and without aphasia in the very early period poststroke. Aphasiology, 30(5), 609-628.

Hough, M., \& Johnson, R. K. (2009). Use of AAC to enhance linguistic communication skills in an adult with chronic severe aphasia. Aphasiology, 23(7-8), 965-976.

Johnson, R. K., Hough, M. S., King, K. A., Vos, P., \& Jeffs, T. (2008). Functional communication in individuals with chronic severe aphasia using augmentative communication. Augmentative and Alternative Communication, 24(4), 269-280.

Kagan, A., Simmons-Mackie, N., Rowland, A., Huijbregts, M., Shumway, E., McEwen, S., Threats, T., \& Sharp, S. (2008). Counting what counts: A framework for capturing real-life outcomes of aphasia intervention. Aphasiology, 22(3), 258-280.

Kinney, J., Wallace, S. E., \& Schreiber, J. B. (2019). The relationship between word retrieval, drawing, and semantics in people with aphasia. Aphasiology, 34(2), 254-274. https://doi.org/ 10.1080/02687038.2019.1602862

LaPointe, L. L. (2011). Aphasia and related neurogenic language disorders (2nd ed.). Thieme Publishers.

Light, J. (1988). Interaction involving individuals using augmentative and alternative communication systems: State of the art and future directions. Augmentative and Alternative Communication, 4(2), 66-82. https://doi.org/10. 1080/07434618812331274657 
LPAA Group, Chapey, R., Duchan, J., Elman, R., Garcia, L., Kagan, A., Lyon, J. G., \& Simmons-Mackie, N., \& Aphasia United Best Practices Working Group and Advisory Committee. (2008). Life participation approach to aphasia: A statement of values for the future. In R. Chapey (Ed.), Language intervention strategies in aphasia and related neurogenic communication disorders (5th ed., pp. 279-289). Lippincott Williams \& Wilkins.

Luria, A. (1972). Traumatic aphasia. Mouton.

Pulvermüller, F., \& Berthier, M. L. (2008). Aphasia therapy on a neuroscience basis. Aphasiology, 22(6), 563-599.

Raymer, A. M., Singletary, F., Rodriguez, A., Ciampitti, M., Heilman, K. M., \& Rothi, L. J. G. (2006). Effects of gesture+ verbal treatment for noun and verb retrieval in aphasia. Journal of the International Neuropsychological Society, $12(6), 867-882$.

Rogers, M. A., Roye, F., \& Mullen, R. (2014). Measuring outcomes in aphasia and apraxia of speech in the context of a learning health care system. Paper presented at the 44th Clinical Aphasiology Conference, St. Simons Island, GA, United States.

Simmons-Mackie, N., Worrall, L., Murray, L. L., Enderby, P., Rose, M. L., Paek, E. J., Klippion, A. (2017). The top ten: Best practice recommendations for aphasia. Aphasiology, 31(2), 131-151. https://doi.org/10.1080/02687038.2016.1180662

Wambaugh, J. L., \& Wright, S. (2007). Improved effects of wordretrieval treatments subsequent to addition of the orthographic form. Aphasiology, 21(6-8), 632-642.

Weissling, K., \& Prentice, C. (2010). The timing of remediation and compensation rehabilitation programs for individuals with acquired brain injuries: Opening the conversation. SIG 12 Perspectives on Augmentative and Alternative Communication, 19(3), 87-96. https://doi.org/10.1044/aac19.3.87

World Health Organization. (2001). International classification of functioning, disability and health: ICF. 